
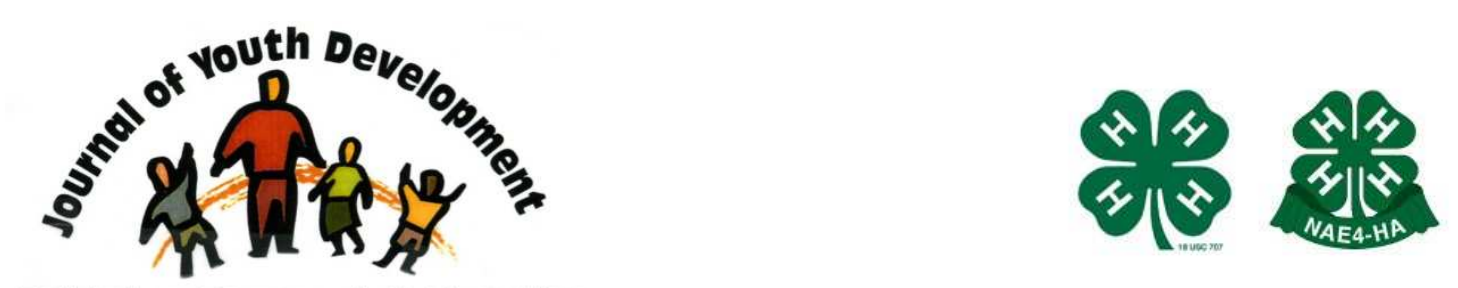

Bridging Research \& Practice

\title{
"You Can Quit Me But I'm Not Going to Quit You:" A Focus Group Study of Leaders' Perceptions of Their Positive Influences on Youth in Boy Scouts of America
}

\author{
Rachel M. Hershberg \\ Institute of Applied Research in Youth Development \\ Tufts University \\ Medford, MA \\ rachel.hershberg@tufts.edu \\ Paul A. Chase \\ Institute of Applied Research in Youth Development \\ Tufts University \\ Medford, MA \\ Robey B. Champine \\ Institute of Applied Research in Youth Development \\ Tufts University \\ Medford, MA \\ Lacey J. Hilliard \\ Institute of Applied Research in Youth Development \\ Tufts University \\ Medford, MA \\ Jun Wang \\ Institute of Applied Research in Youth Development \\ Tufts University \\ Medford, MA \\ Richard M. Lerner \\ Institute of Applied Research in Youth Development \\ Tufts University \\ Medford, MA
}




\title{
JOURNAL OF YOUTH DEVELOPMENT \\ bridging research and practice

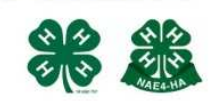

Volume 10, Number 2, Summer 2015

Article 151002FA001

\section{"You Can Quit Me But I'm Not Going to Quit You:" A Focus Group Study of Leaders' Perceptions of Their Positive Influences on Youth in Boy Scouts of America}

\author{
Rachel M. Hershberg, Paul A. Chase, Robey B. Champine, Lacey J. Hilliard, \\ Jun Wang, and Richard M. Lerner \\ Tufts University
}

\begin{abstract}
As part of a longitudinal, mixed-method study with Boy Scouts of America, we conducted five focus groups with a diverse group of 46 program leaders in order to better understand their perceptions of how they influence youth. Drawing from grounded theory analysis methods, we found that leaders believed they promoted positive youth outcomes, including character and selfconfidence, through caring youth-leader relationships and facilitating opportunities for youth to participate in and lead skill-building activities and apply skills in different contexts. Leaders differed in the particular outcomes that they emphasized. Implications of these findings for future research and practice are discussed.
\end{abstract}

\section{Introduction}

Each year, millions of American children participate in out-of-school time (OST) programs (Vandell, Larson, Mahoney, \& Watts, 2015). According to the Positive Youth Development (PYD) perspective, high-quality OST programs (e.g., Scouting, 4-H, or Boys \& Girls Clubs) may constitute key developmental assets in the ecology of youth. These assets have the potential to promote positive and healthy outcomes, including improved psychological and physical health, academic achievement, civic engagement, enhanced personal motivation and future orientation, among others (Benson, Scales, \& Syvertsen, 2011; Lerner, Lerner, Bowers, \& Geldhof, 2015). Given the increasing participation of youth across the U.S. in OST programs, there is a growing interest among scholars and practitioners in research about specific OST program contexts, and about what facets of these contexts contribute to what outcomes, among what specific populations of youth (Vandell et al., 2015)

The PYD literature suggests that the highest quality and most effective OST programs incorporate at least three key program features (termed the "Big Three" by Lerner, 2004): in 
the context of safe and supervised spaces (Theokas, Lerner, Phelps, \& Lerner, 2006), they provide youth with opportunities to develop and sustain positive relationships with adult mentors, to develop important life and leadership skills, and to apply these skills through participation in valued activities (see Blum, 2003; Lerner et al., 2015; Roth \& Brooks-Gunn, 2003). This research emphasizes in particular the influences of caring relationships between youth and adult mentors on youth outcomes (Rhodes \& Lowe, 2009; Sullivan \& Larson, 2010). According to Rhodes and Lowe (2009), adults in OST programs are in a unique position to provide emotional support, guidance, and advice to youth in their care, and may function in a mentor capacity through building mutual commitment, respect, and trust (Rhodes \& Lowe, 2009). Positive youth outcomes associated with mentoring relationships include increased selfesteem and confidence (Rhodes \& Lowe, 2009).

Given that youth-leader relationships appear to function as an important means through which program participation positively impacts young people's health and well-being, more needs to be known about the processes that occur in successful youth-leader relationships within specific OST program contexts (Larson, 2006). In other words, how do staff and adult leaders within and across specific OST programs help to cultivate young participants' healthy cognitive, emotional, and social growth? Do the processes in which leaders engage to positively influence youth differ depending on the program context and characteristics and experiences of youth served in these contexts?

The present research sought to contribute to addressing these questions as part of an ongoing longitudinal and mixed-method collaborative assessment of the impact of the Boy Scouts of America (BSA) program on youth: the Character and Merit Project (CAMP; see Hilliard et al., 2014). Specifically, the CAMP Study is a partnership with the leadership of BSA in the greater Philadelphia region, the Cradle of Liberty (COL) council (we note that our partner organization elected to be identified in this publication). With the COL, we developed the larger CAMP Study to assess:

1. whether BSA constitutes a high-quality OST program that positively influences character and other Positive Youth Development (PYD) outcomes; and

2. how BSA program components may influence these outcomes in youth.

In the current investigation, we sought to contribute to the knowledge base pertinent to, and theory development about, the processes through which youth-leader relationships in the context of BSA may contribute to positive youth outcomes. In a program such as BSA, adult leaders' perspectives and understandings may be essential to optimizing the positive impacts of the program on the youth served therein, as these leaders are integral to the program and are charged with its delivery. We, therefore, focused on leaders' perspectives of these relationships, and of how the BSA context may positively influence youth. In addition, we aimed to learn more about leaders' perceptions of their influences on youth within a specific arm of BSA programs in Philadelphia serving ethnic minority youth from lower-income and urban communities: ScoutReach. The ScoutReach program differs from the traditional program because meetings typically take place right after school (as compared to during evenings), are led by paid staff (as compared to parent volunteers), and have minimal parent involvement. Accordingly, we conducted five focus groups with leaders from the COL, including three focus groups with just ScoutReach leaders, to elicit their perspectives about their influences on youth outcomes as well as the ways in which the BSA and ScoutReach program contexts may influence youth. This investigation is an important contribution to research and practice with BSA programs in particular, as much of the research with BSA has focused on broadly exploring potential impacts of Scouting on the prosocial development of youth (e.g., Harris Interactive, 2003; Jang, 
Johnson, \& Kim, 2012; Louis Harris \& Associates, 1998; Polson, Kim, Jang, Johnson, \& Kim, 2013Kim2013), neglecting to consider potentially distinct processes and outcomes, or perspectives about these processes and outcomes, among different groups of leaders who participate in the program. As such, despite making important contributions to the research on OST program influences on youth outcomes, this literature lacks in-depth or qualitative information about the specific processes through which components of BSA (e.g., leader-Scout interactions, BSA curriculum, or BSA activities, such as camping, outdoor recreation, etc.) may potentially influence specific developmental outcomes (e.g., PYD or character development) among specific groups of Scouts (e.g., ScoutReach youth). In addition, few in-depth qualitative studies have been conducted with leaders in BSA (or in similar youth-serving programs) to explore their understandings of their roles and/or the ways in which they, and the program, work together to influence PYD (Larson, 2000, 2006).

This gap in the research is of concern because previous studies with youth-serving practitioners and youth involved in other OST programs found that practitioners, youth, and scholars often do not use the same terms when describing the characteristics and attributes that comprise PYD (King et al., 2005). Discrepancies between program leaders' understandings of the processes through which they influence youth and those described in the PYD literature would suggest that both sources of knowledge need to be enhanced to more accurately reflect the other (King et al., 2005). Leaders' conceptions of how they positively influence youth could, for example, inform future PYD research and measurement techniques, as well as research and policy priorities related to promoting optimal developmental outcomes among America's diverse youth, and in the very OST program contexts that rely on the participation of adult leaders. Thus, in order to elucidate the processes through which specific OST programs may impact youth, it is essential to explore diverse leaders' understandings of how they influence youth, and to ascertain if (as we shall report) leaders' perceptions align with existing research on effective youth development programs (e.g., see Lerner, 2004; Lerner et al., 2015).

\section{The Current Investigation}

Accordingly, the aim of this investigation was to contribute to the knowledge base pertinent to, and theory development about, the processes through which youth-leader relationships in BSA activities may contribute to positive youth outcomes by focusing on the perspectives of a diverse group of leaders in BSA. We focused on the perspectives of different groups of leaders within the COL, with different histories in BSA and serving different groups of youth (as described below), to generate more in-depth information about the various kinds of youthleader relationships within this organization and the processes through which they may positively influence youth outcomes for different groups of youth. The specific research questions guiding this investigation were:

1. what are leaders' perceptions of their influences on positive outcomes in youth, and how do they correspond with findings from other research about effective practice in youth development programs?;

2. what, if any, variations can be identified in leaders' descriptions of the ways in which they promote positive youth outcomes within the context of BSA?; and

3. given the recent innovation of ScoutReach as a vehicle of BSA program delivery to predominantly ethnic minority, urban youth, how do ScoutReach leaders' perceptions of the impact of BSA on positive youth outcomes compare to those of other leaders?

To address these questions, we conducted iterative analyses of five focus groups with leaders. We drew from a constructivist grounded theory approach (Charmaz, 2006). As we describe 
below, we were able to identify parallels between leaders' descriptions of their views of how they may influence positive youth outcomes in BSA and PYD scholarship on how youth may develop positively in OST programs (e.g., Lerner, 2004; Lerner et al., 2015).

\section{Method}

The five focus groups were conducted in the context of the CAMP Study (see Hilliard et al., 2014 for more information). The COL implements its programs following the national mission of BSA, which emphasizes youth character building and training in leadership as well as responsible citizenship (BSA, 2014). The COL serves 10,000 Scouts throughout the Council, and its programs are facilitated by mainly volunteer leaders from 250 packs throughout the region. In addition, the COL includes various staff members who provide support to volunteer leaders throughout the region.

\section{Participants}

The five focus groups we facilitated as part of the CAMP Study were conducted between October 2012 and May 2013. One focus group included leaders identified by BSA as "exemplary," another group included leaders who volunteer at the district level (referred to herein as district leaders), and three focus groups were conducted with leaders from the ScoutReach division of BSA. The leaders in the "exemplary" group were identified by volunteers who have worked in the COL for many years, and visit packs in the COL on a regular basis. According to these volunteers, leaders were identified as "exemplary" because their packs and/or troops had met many of BSA's benchmarks under their leadership (e.g., a significant percentage of their Scouts participated in BSA summer camp, met fundraising goals through popcorn sales, and advanced from one level of Scouting to the next). In addition, the experienced volunteers subjectively identified these leaders to be of "high quality" (C. Bolger, personal communication, October 25, 2012). These "exemplary" leaders had a range of experience in Scouting, spanning months, years, and decades. Of the 14 "exemplary" leaders who participated in the focus group, 11 were European American and three were African American. In addition, ten were male and four were female.

District leaders are experienced volunteer leaders who also serve youth throughout the BSA program. These leaders work at the district level, which means that they volunteer their time to assist many Cub Scout packs and Boy Scout troops throughout one of the twelve regional districts in the greater Philadelphia area. We recruited these leaders for participation in the focus groups because we believed that their insights would be beneficial in light of the potential long-term, intraindividual (within-person) changes that they may have observed in boys who participated in the program for many years. Of these 14 participants, 12 were European American and two were African American. This group included 13 male and one female participant.

Finally, we conducted three focus groups with ScoutReach leaders to examine their perceptions of their influences, and the influence of BSA, on the PYD outcomes of the youth they served. Eighteen leaders participated across these three groups; 14 were African American, three were European American, and one was Latino. Twelve of these participants were female and six were male. In total, 46 BSA leaders across the COL participated in focus groups. Of this sample of participants, $37 \%$ were female and $44 \%$ were African American or Latino. 


\section{Procedure}

All of the focus groups took place at sites throughout the greater Philadelphia area, where leaders in the COL meet for monthly "round table" discussions as part of their leadership in the BSA. Round table meetings provide an opportunity for leaders in different arms of the COL to come together and learn about new trainings, share ideas from their work with Scouts, and plan for district- or council-wide activities.

We developed a semi-structured focus group interview protocol to guide our focus group discussions. The interview protocol included questions about the adult leaders' experiences in Scouting, how they believed they influenced Scout outcomes, and what outcomes they believed they impacted in the context of BSA. We also asked leaders about any potential challenges they experienced in implementing the BSA program. Sample questions included: "How do you think that Scouting impacts kids?" and "What are some of the challenges that you experience in Scouting?"

Prior to facilitating focus groups and moving through our semi-structured protocol, participants signed consent forms indicating their willingness to participate and be video-recorded. Each focus group lasted approximately one hour. Although our interview protocol addressed the same topics in each of the five focus groups, in light of the interactive nature of focus group discussions (Kitzinger, 1995), different topics arose in each group that were followed up with clarifying questions. For example, in the focus group with "exemplary leaders," co-facilitators inquired about what attributes an ideal pack and leader possess, given discussions that emerged about high-quality leaders. In addition, in response to questions about challenges to delivering BSA, ScoutReach leaders engaged in detailed discussions about how they viewed some of the main challenges they experienced in implementing BSA activities as potentially unique to the lives of ScoutReach youth (e.g., safety concerns). These discussions were, as well, followed up with clarifying questions. Shortly after focus groups were conducted, audio recordings of the sessions were sent to a transcription service. Upon receipt, transcripts were checked for errors and corrected accordingly.

\section{Plan of Analysis}

Three of the co-authors (Hershberg, Chase, \& Champine) iteratively analyzed the data, drawing from a constructivist grounded theory approach (Charmaz, 2006). We began immersing ourselves in the data by reading through each of the five transcripts from the focus groups and discussing the topics that arose within and across focus groups. Next, we decided to more systematically focus on data excerpts wherein participants discussed components of BSA that they believed impacted youth development, their interactions with youth in BSA, and the positive outcomes they believed youth developed through participation in BSA. Through reviewing these focus group excerpts of interest, we agreed that we also needed to include sections from transcripts wherein leaders discussed challenges they experienced to implementing BSA programs and activities, as these data often included leaders' descriptions of challenges they confronted in delivering a high-quality Scouting program to youth. These descriptions explained, in part, leaders' understanding of which components of BSA influenced outcomes in youth. We excluded data from transcripts that focused on, for example, technical aspects of being an adult leader in Scouts (e.g., strategies that leaders used to increase parent participation).

After selecting data excerpts of interest, we engaged in an open-coding of the data that was directed toward identifying: 
1. leaders' descriptions of the processes in which they engaged to influence positive outcomes in Scouts;

2. program components that leaders believed have positive impacts on youth outcomes; and

3. specific positive outcomes leaders identified.

We defined positive outcomes broadly, as any positive characteristic or behavior in Scouts to which leaders referred when they discussed how Scouting, and their interactions with youth in Scouting, positively influenced youth.

Throughout the open-coding process, we each engaged in multiple forms of memo writing to identify and reflect on our assumptions of the data, and assist with moving our analysis from being descriptive to more abstract and explanatory (Charmaz, 2006; Strauss \& Corbin, 1998). This step was an important part of our analysis, and increased the trustworthiness of our findings (Morrow, 2005), as each of the three co-authors involved in data analysis had been a part of the CAMP Study since August 2012, and had ideas about what processes leaders might identify as influencing positive outcomes in the youth they served. We reviewed our reflective memos together throughout the analysis to remain open to identifying and exploring terms, concepts, and processes presented by participants in their own words that may not reflect the PYD language (following the example of King, et al., 2005).

Finally, analytical memo-writing enabled each author to identify the more salient themes, or connections among codes (Braun \& Clarke, 2006), within and across the three groups of participants. Through this process of memoing and discussing each other's memos, we agreed that there were, indeed, important shared understandings articulated by leaders across each focus group regarding how they and the BSA program were perceived to impact positive youth outcomes, as well as important variations between groups (Corbin \& Strauss, 2008). We also developed a visual diagram (in keeping with grounded theory methods, Charmaz, 2006) that best represented our jointly constructed understandings of leaders' views about the general processes through which they and the program influenced positive outcomes in Scouts, as well as their views about which outcomes they influenced in youth.

Specifically, through our analysis we generated a model of potential BSA program influences on PYD in the youth they serve that corresponds with the "Big Three" conception of effective youth development programs, as described in detail below (see Figure 1). 
Figure 1

A conceptual model of how characteristics of the BSA program and program leaders are perceived (by leaders) to influence the positive development of Scouts.

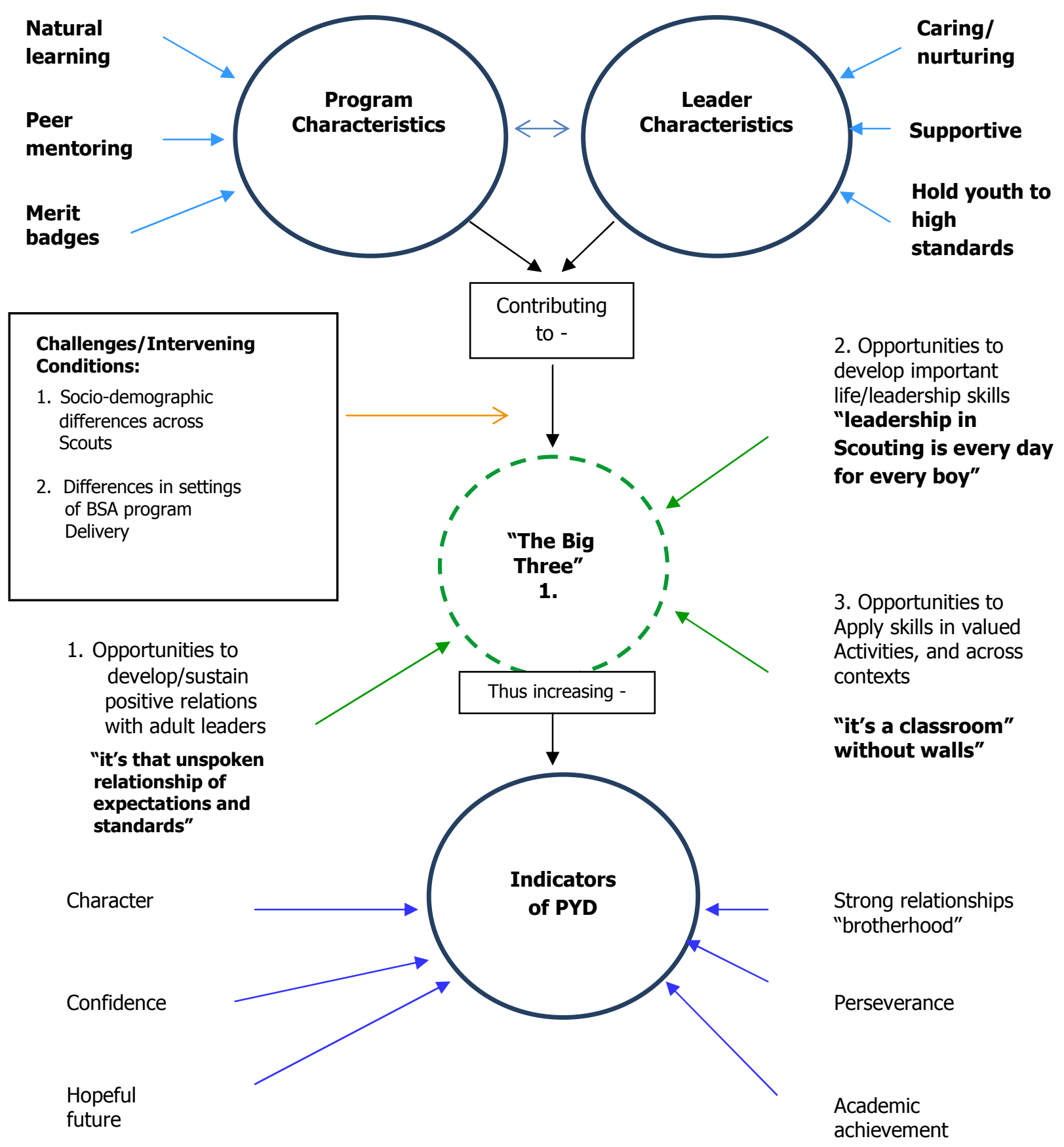




\section{Results}

The aim of this investigation was to contribute to the knowledge base pertinent to, and to the development of theory about, how leaders across one region of BSA, with different histories and experiences in Scouting, may understand their influences and programmatic influences on positive youth outcomes. We also aimed to identify potential variations in leaders'

understandings of these influences, and sought to understand these influences in the context of both BSA and in relation to the PYD literature (e.g., Lerner, 2004). Specifically, we assessed if leaders' understanding corresponded to the model of youth development program influences on attributes of PYD, such as character (Lerner et al., 2015), reported in reviews of OST literatures (e.g., Blum, 2003; Lerner et al., 2015; Roth \& Brooks-Gunn, 2003). We assessed if leaders' perceptions corresponded to the "Big Three" model of effective youth development programs in particular (Lerner, 2004). We also focused on understanding if, and in what ways, ScoutReach leaders' experiences and perspectives differed from those of other leaders.

We present below our findings pertinent to each of the research questions. Specifically, we provide examples of the core general processes and some of the positive youth outcomes we identified in our analyses, highlighting similarities across focus groups. We note below that some leaders described the PYD-promoting processes of which they are a part as intertwined with the BSA program context in which they and the youth interact. We, therefore, point out some of the specific BSA program components, such as the BSA curriculum, Scout Law, and Scout Oath ${ }^{1}$ that leaders identified as promoting positive youth outcomes. We then identify variations in leaders' descriptions of how they influence PYD and, specifically, how ScoutReach leaders' descriptions differ from those of "exemplary" and district leaders.

In Figure 1, through our conceptual model, we represent these main findings, which correspond to the "Big Three" characteristics of youth-serving programs described in the PYD literature (Lerner, 2004). As depicted in this figure, we found that leaders believed they influenced youth, through interactions between them and the BSA context (e.g., the BSA curriculum, the merit badge system, the nature-based context of many Scouting activities). Leaders described that in the context of BSA programs, and through their own interactions with the BSA curriculum and program components, they were able to engage in supportive relationships with youth, engage youth in skill building activities, and encourage application of these skills in and outside of Scouting.

Leaders across groups reported engaging in these same general processes, and through these processes, promoting most of the same positive outcomes (e.g., character, confidence, hopeful future orientations, perseverance, academic competence) in Scouts. However, there were also variations or nuances in the specifics of the processes and outcomes emphasized by different groups of leaders, which appeared to be related to variation in leaders' experiences in Scouting, and to variations among the youth each group of leaders served in Scouting. These nuances also reflected the distinct challenges each set of leaders confronts as they delivered the BSA program to Scouts, and are represented in our model as "intervening conditions," drawing from the constructivist grounded theory analysis method (Charmaz, 2006). In particular, ScoutReach leaders, uniquely, described challenges associated with delivering BSA to youth in an urban

\footnotetext{
${ }^{1}$ The Scout Oath (or Promise) is: "On my honor I will do my best, To do my duty to God and my country and to obey the Scout Law; To help other people at all times; To keep myself physically strong, mentally awake, and morally straight." The Scout Law is: A Scout is trustworthy, loyal, helpful, friendly, courteous, kind, obedient, cheerful, thrifty, brave, clean, and reverent" (BSA, 2014)."
} 
setting. These leaders also discussed their beliefs that providing BSA to these youth was especially important because many of them lacked positive role models in their lives. We also found that variations in leaders' descriptions of the PYD-promoting processes and outcomes they believed they facilitated for youth helped to explain the particular facets of youth-leader relationships, within the context of BSA programs, that may be related to specific outcomes for specific youth. We describe these findings in detail below and, when possible, use illustrative quotes collected from the focus groups.

\section{Leaders' General Perceptions of Their Influences on PYD: Correspondence with the "Big Three" Model}

The first Research Question addressed leaders' perceptions of their influences on positive outcomes in youth, and if they corresponded to the PYD literature about the features of OST programs that are effective in promoting PYD (e.g., King et al., 2005; Lerner, 2004). As noted, through our analysis of the five focus groups, we found that BSA leaders had shared understandings of the general processes through which they influenced PYD and character outcomes in Scouts, and that these understandings reflected much of what PYD researchers have described as "the Big Three" (Lerner, 2004). That is, we found that leaders understand themselves to influence positive youth outcomes through:

1. engaging in "caring" relationships with Scouts;

2. providing Scouts with opportunities to learn new skills and scaffold or "lead" younger peers' skill development; and

3. providing opportunities for Scouts to apply these skills during Scout meetings, in "natural learning environments," and in other contexts, such as schools.

Through engaging in these processes in the context of the Scouting program, each set of leaders in this study agreed that they are contributing to a variety of outcomes, such as Scouts' increased self-confidence, independence, leadership skills, happiness, sense of brotherhood, problem-solving abilities, self-regulation skills, and academic competencies. These leaders also agreed that components of the BSA program (e.g., the merit badge system, teamwork activities, Scout Oath), and the ways in which leaders deliver this program to Scouts (e.g., explaining the "real-life" meaning behind each badge and attribute in the Scout Oath), contribute to Scouts' application of the skills they learn in Scouting to other contexts (e.g., at home and school). In the words of one district leader, although BSA meetings occur only weekly, "leadership in Scouting is every day for every boy."

\section{Caring Youth-Leader Relationships}

In each of the five focus groups, leaders identified that developing caring relationships with youth was one of the main ways in which they had a positive impact on Scouts' development. Although some of the details of what comprised these youth-leader relationships varied both within and across focus groups, all leaders expressed that caring and support were features of the relationships they developed and attempted to maintain with youth through their participation in BSA. For example, one ScoutReach leader explained:

You'll be surprised how many... after years go by, [are like] "I really like her because she took the time just to smile at me. She took the time just to say I care." That little one hangs on your shoulder, he will think of you for years and years to come because no other man, uncles, cousins...[or anybody] else, did that for him. "A teacher, a man of this stature took the time out for me? Little old me?" 
Across focus groups, leaders also shared similar views about how caring youth-leader relationships function to positively impact youth. Both ScoutReach and district leaders shared, for example, how caring for Scouts means holding them to high expectations and standards, which encourages them to try and be their best. One ScoutReach leader explained: "It's that unspoken relationship of expectations and standards, and you know...I don't have children, but I guess because there's that parental aspect that we talked about earlier...they still need that nurturing. We give it to them."

Echoing these sentiments, a district leader explained further how components of the BSA context facilitate this supportive and caring youth-leader relationship, and related outcomes in Scouts, such as perseverance. In response to the facilitator's question of how Scouting impacts youth, a leader noted: "[It] gives them an opportunity to grow at the pace they're comfortable with, with very specific, positive role models and positive guidelines and positive objectives." Another leader in that same group shared how, within this supportive Scouting context, leaders provide encouragement in various ways. He illustrated this common feature of youth-leader relationships further by asking his fellow leaders: "How many of us have said 'Just keep trying?"' Participants in this district leader focus group responded with nods of agreement. A participant in the "exemplary" leader focus group also shared his views that a supportive and "good" leader in BSA "tries to understand what each youth is going through during a critical period of his life, and to be patient with him, rather than judgmental, if and when he falls short of expectations or short of living up to the Scout Oath and Law."

In short, leaders across focus groups shared the view that one of the main ways they perceive themselves as influencing positive outcomes in Scouts is through caring about them and showing they care. Leaders demonstrate their concerns for the Scouts they serve by "holding them to high standards," telling them to "just keep trying," and through "being patient with them" when they may fall short of leaders' expectations. These findings align with one of the "Big Three" characteristics of effective youth programs described earlier; that is, that programs should aim to foster the development of positive and sustained relationships between youth and adults (Lerner, 2004). These findings also suggest that adult leaders in Scouting may act as role models or mentors within the context of community-based, after-school programs (Bowers et al., 2011; Lerner, Lerner, \& Benson, 2011). The developmental benefits associated with mentoring may derive from the support and role-modeling provided as part of these youth-adult relationships, described, as well, by the leaders in this study (Rhodes \& Lowe, 2009; Rhodes, Spencer, Keller, Liang, \& Noam, 2006). As described in the following section, these components of caring youth-leader relationships appear to work in tandem with the opportunities provided in BSA for enhancing various skills to promote positive outcomes in youth.

\section{Opportunities for the Development of Leadership, Character, and Life Skills}

In addition to describing the content and function of caring youth-leader relationships in BSA, across focus groups, leaders shared similar examples of how the BSA activities and curriculum they delivered to Scouts provided numerous opportunities for youth to scaffold their younger peers and develop leadership, character, and life skills. We identified that leaders also linked engaging in these activities to the development of self-regulation skills and positive youth attributes, such as tolerance, as described below. In their descriptions of these opportunities for skill development, leaders provided many examples of the PYD-promoting processes they facilitate for youth, and of the PYD outcomes they perceive as resulting from these processes. 


\section{Scaffolding and Leadership Development Opportunities in BSA}

Leaders across focus groups frequently referred to the leadership development opportunities they facilitated for youth when they described how BSA promoted positive outcomes. Specifically, leaders across focus groups described how youth were given opportunities to take the lead in activities throughout their participation in Scouting, which enabled them to become leaders in other facets of their lives. All leaders also described how leadership development becomes even more core to Scouting as youth transition from Cub Scouts to Boy Scouts (which usually occurs as $5^{\text {th }}$ graders transition to $6^{\text {th }}$ Grade).

A ScoutReach leader shared what this support looks like during a BSA meeting: "Normally, we allow our older boys to kind of run the snack, pass out the snack, and do these responsibilities." Another leader shared: "Sometimes what I'll do is, depending on my activity, I'll put the Webelos [Scouts in $5^{\text {th }}$ Grade] in charge of the little ones to make them become - like the steps they need to transition to the Boy Scout aspect of taking charge and leading." Similarly, a district leader shared his observation that leadership opportunities must be provided throughout youth experiences in Scouting: "I think the leadership is an important part - what they're learning coming up through the program. The leadership is developed over a period of time, by watching the older boys and mimicking them." Another "exemplary" leader explained that she believed this youth-led and general leadership focus of Boy Scouts was vital to the success of troops and packs with whom she works, explaining that, for this reason, "this year for the first time ever, we [Boy Scouts and Cub Scouts] sold camp cards together [i.e., restaurant coupons], we sold popcorn together... so you have the bigger kids mentoring the little kids."

Although leaders agreed that BSA promotes youth leadership through providing opportunities for older youth to mentor their younger peers, they were also clear that good adult leaders must be present to facilitate this process. For example, one district leader noted that:

You need adults for a couple of reasons. You need adults to be good examples. You need adults to keep an eye on them, and for certain obvious legal reasons, like they can't drive themselves around. But we're trying to create leadership qualities in them. We're trying to make them be the ones that demonstrate leadership. Then you just have to herd the young ones into the group and let them feed off of the older ones. In a well-run troop, that's the model. The boys run the meetings. The boys delegate responsibilities. They have patrol leaders. They take care of things. The adults just do the things that adults have to do.

Another district leader, expressing his agreement, noted: "the adults set the tone." Thus, across focus groups, leaders expressed that adults are an important part of BSA, even as youth transition from Cub to Boy Scouts, or from $5^{\text {th }}$ to $6^{\text {th }}$ Grade. Adults are important not only for practical reasons (e.g., providing transportation of youth from one meeting to the next), but because they, as one district leader expressed, "set the tone" for the character development activities and processes in which youth are expected to engage through Scouting.

\section{Character Development Opportunities and Related Outcomes in BSA}

Character, like leadership, is an attribute that BSA explicitly targets in its curriculum and activities, and the skill-building opportunities provided therein. One district leader explained: "...once a week, they repeat the Scout Law. If you keep repeating that, it becomes part of you." Another leader explained the substance of the Scout Law and how leaders believe they play a part in the process of character development through the Scout law. He noted: 
The Scout law has the point - I mean that's the character and stuff, right there. When you can stand up and look at a guy and say, 'Well, he's trustworthy, he's loyal, and he's always helpful' - You go down the list and say, 'Wow, there it is.' It's right there. I mean it's really neat when you see all of those things pop out of a kid because of what he's been involved with. And of course, you sit there and you say it, but you also talk about it. Like the Scout Master's Minute and you do the Scout Master Minute ${ }^{2}$ at the end of the meeting. You stand up there, and you talk about some of these points. You really hit home with a story or something. It sinks in after a while.

Character development was also identified as one of the main outcomes leaders try to influence through their relationships with youth. Specifically, leaders noted that they try to influence character in youth through modeling good character themselves. An "exemplary" leader explained that adult leaders in BSA influence character by: "Having people who will serve as the role models...You have to - the leader who, when he or she says, 'I'm going to be there,' is there...I mean, that goes a long way in demonstrating trustworthy." Another "exemplary" leader underscored that, in order to influence character in youth, leaders cannot be "holding them [the Scouts] to different standards than you apply to yourself."

In addition to communicating the meaning behind the character-based curriculum in BSA (e.g., the Scout Oath), and modeling character in their own lives, leaders shared the understanding that character develops through the prevention of problem behaviors and the promotion of selfregulation skills. Leaders also described how these processes and outcomes are meant to be facilitated by the Scouting context. One leader noted: "Cubs also have to accomplish X number of tasks in order to advance. It gives them a goal to seek. They have to advance in a certain way. In other words, they have to focus on what they're doing in order to achieve the different level." Another leader explained:

The one thing that everybody in the world can have if they want is dedication and perseverance. That's the two things. If you want to excel in Scouting, you just have to excel in those two qualities. Everything else will be within your reach. You don't have to be the fastest or the strongest, or smartest, or anything. You have to excel in dedication and perseverance. That's something we can give to every kid.

Along these same lines, ScoutReach leaders believed that Scouts develop character through engaging in fun, skill-developing activities that influence them to build strengths and disengage from problem behaviors, as "good behavior" is a requirement of being in ScoutReach. As one leader noted: "They want to be a Boy Scout, so they don't get in trouble." Through attending enjoyable ScoutReach meetings, these leaders perceive that youth develop a desire to maintain their participation in Scouting, and to fulfill this desire they avoid getting in trouble.

In addition, leaders believed that youth are encouraged to maintain their participation in Scouting because the program provides them with the opportunity to "try new things" that they may not experience outside the Scouting context, and in an environment in which they feel "safe" exploring. For example, a ScoutReach leader shared: "They actually feel safe in the environment. It's okay to mess up." A district leader also indicated: "There's never a fail. There's only pass or incomplete. You can always complete it at your own pace. That's the other

\footnotetext{
${ }^{2}$ The "Scoutmaster's Minute" is when, at the close of every weekly meeting, the leading adult volunteer (Scoutmaster) shares a short parable with all of the Scouts in order to teach a BSA virtue such as loyalty or honesty.
} 
beauty of it is, even though there's sort of some age-specific things, you're encouraged to advance according to your capabilities."

Leaders also explained the idea that having opportunities to fail in a safe environment, while being encouraged to develop new skills, also provides youth with opportunities to experience successes and rewards. All leaders indicated that they believed Scouts' experiences of multiple successes within the context of Scouting resulted in youth having increased self-confidence, a core outcome mentioned throughout focus group discussions. In describing changes she witnessed in a Scout who "came out of his shell" through Scouting, one ScoutReach leader observed that:

We had to really pull out of him the questions we were asking him. But ever since he made that birdfeeder and put it out my window, he's just [changed]... since he made that birdfeeder and put it up there, he feels like now he can do just about anything.

Expressing similar views, a district leader explained: "It's not graded on an essay. It's not graded on - they don't get an 80. They don't get an A, B, C. They earn the patch. They do, and they accomplish, and that is very different. It's rich in reward. It's very accessible." Another district leader also shared his perception that the "reward" system contributed to improved selfesteem for youth in Scouting: "... Once they learn these values that work and get them acceptance, and appreciation and approval, they feel a lot better about themselves. I think that's the heart of it."

As illustrated above, leaders in ScoutReach as well as district and "exemplary" leaders, shared the belief that engaging in a program within a safe environment that provided youth with opportunities to set and pursue goals, gain new skills, and be rewarded for them (e.g., through the merit badge system), led to the development of character and related positive outcomes, such as enhanced self-regulation and self-confidence. The importance of having access to a safe and supervised environment is echoed in the developmental literature on the components of effective youth programming (Lerner, Alberts, Jelicic, \& Smith, 2006; Lerner \& Thompson, 2002; Theokas et al., 2006). Leaders also shared the belief that opportunities for engaging in these processes and developing these outcomes should be provided to all youth, in line with what they view as BSA's commitment to promoting inclusiveness and tolerance. As one leader explained:

Scouts has always been the place where young people can go that maybe think they're different, feel different, and not be different. Scouts is where I personally learned that we're all green. We're all khaki. It doesn't matter where you're from or what you look like, or what color your skin is. I learned that in Scouts.

A ScoutReach leader also indicated that Scouts should be for everyone, and that inclusiveness was something she also tried to model for Scouts: "They know to be a Cub Scout, all you need to do is be yourself, be respectable, and be a good citizen"

\section{Opportunities for Life Skill Development}

In addition to developing leadership and character, as well as enhancing self-regulation and self-esteem, BSA was described by leaders as providing many opportunities for the development of life skills. For example, one ScoutReach leader noted:

I teach them how to do a fire drill, how to do CPR, all of that stuff. We teach them all of that stuff. Also something they like a lot is, I make believe I'm 911. "This is 
911? What's your emergency." "There's a crazy person," [they say], then you [go], "is he inside?" So you make it like it's a real call, and they have a blast.

District leaders also spent much of their focus group discussing all of the valuable life skills youth can learn in Scouting. For instance, one leader shared: "Kids that I've seen coming through our troop, whether they're Eagle Scouts or whether they've been in a program two years or something like that, they generally know how to cook, and things, which are good skills."

\section{Opportunities to Apply Skills Learned in Scouting across Contexts}

Participants in all of the focus groups provided examples of how youth apply the skills they learn in BSA in a variety of Scouting activities, as well in other contexts. They also believed that the positive outcomes they develop through Scouting impact other contexts. The context that was referenced most frequently was school. For example, one ScoutReach leader shared: "They're into first aid. We made each one of our boys - well, they made, little first aid kits. When we want to go out to the schoolyard at lunchtime, they take those first aid kits out, and if anyone falls or gets scraped, they see - you know. So I let them put it in action." Another ScoutReach leader indicated that:

You are teaching them something but then you're saying, 'Hey, now apply it. Build the tent. Figure out how to make a path. Make a plan. You're going to be in the woods for two weeks. How are you going to eat? How are you going to wash?' So we teach them the skills and then immediately tell them or show them, or make them apply it.

District leaders, in particular, emphasized how skills learned in Scouting could influence academic competencies as well. As one leader noted:

Our grading system teaches the boy that if you try enough, you're going to get it. That translates into, I think, greater effort when it comes to academics. So the kid that is, perhaps, the $\mathrm{D} / \mathrm{C}$ student because of sheer effort, then they start becoming an A and B student. It doesn't always happen, all right, but it does give the kid a roadmap to success in academics. It's usually right through effort, and that's where it all comes - I mean we reward effort.

\section{Variations in Leaders' Descriptions of PYD in BSA}

The second Research Question focused on exploring possible variations in leaders' descriptions of the ways in which they promote positive youth outcomes within the context of BSA. Accordingly, in addition to shared understandings of their perceived influences and program influences on Scout outcomes, we identified differences between each set of leaders in regard to the particular processes and outcomes they emphasized. Just as ScoutReach leaders drew from their specific experiences in BSA as they described how the attributes of the Scouts they served (and of their communities) influenced their delivery of BSA to youth, district leaders reflected on their experiences serving Cub and Boy Scouts over many years, and provided a "long view" about how they believed Scouting impacts youth. In addition, "exemplary" leaders drew from their own experiences as they presented their views of the components of "good" adult leadership in Scouting that enabled packs to excel.

Although there were differences between each set of leaders in the descriptions they provided, "exemplary" and district leaders were more similar to each other than either group was to 
ScoutReach leaders. As described in more detail in the subsequent section, ScoutReach leaders uniquely focused on challenges they experienced in delivering the BSA curriculum in urban settings. We provide select excerpts from these data to illustrate these nuances (pointing out similarities among leader groups throughout). We note that, in these excerpts, potential links among specific leader-generated processes, and the PYD outcomes they promote, become clearer.

\section{"You can quit me, but I'm not [going] to quit you"}

In focus groups with ScoutReach leaders, more so than in the other groups, the desire to provide needed "nurturing" and support, as well as confirmation to the youth that they "believed in them," was a recurring theme. For example, one leader said: "It's a great opportunity for the kids, as well as for us leaders, just to help influence kids in a positive way. At the end of the day, they need that nurturing. They need it so desperately. They - for a lot of our boys, there are no men."

Related to ScoutReach leaders' focus on the importance of providing nurturing, support, and encouragement to the youth they served was their unique focus on how, through Scouting, youth developed more positive and hopeful future orientations. One ScoutReach leader explained why the outcome of becoming hopeful was important, especially for ScoutReach youth: "there are so many kids who like, even with Obama being President...there are so many kids that truly would have never thought that it could be me, you know. They need those role models." Thus, ScoutReach leaders expressed their perceptions that the youth they serve are in need of leaders who can develop strong and supportive relationships with youth, and, through these relationships, model character as well as who the youth can hope to become in the future. According to ScoutReach leaders, BSA provides youth with the opportunities to develop these important relationships and, in turn, these positive outcomes.

ScoutReach leaders noted, however, that delivering BSA to youth with these needs, and in urban settings that are far removed from nature, is not without its challenges. However, one ScoutReach leader perceived a positive impact of delivering BSA to youth in urban Philadelphia:

It's like, what could they be doing in a house by themselves, some of the dangers?

You know, house fires or making food by themselves... I just love the fact that I know they're safe. They're not allowed to leave the room without me. Oh, you have to go to the bathroom? We're all going to the bathroom. They need to be safe.

Thus, despite potential challenges associated with delivering BSA as an after-school program in schools in downtown Philadelphia, ScoutReach leaders also perceived the availability of ScoutReach to youth in the "inner city" as a strength of the program.

\section{"It's our classroom without walls"}

The challenges described by ScoutReach leaders of being tasked with delivering BSA in an urban setting directly contrasts with the emphasis by district leaders on the "natural learning" component of Scouting. District leaders described their experiences in BSA as revolving around learning in nature:

It's our classroom without walls, it's the outdoors. We accomplish most, we learn most when we are taking that patrol and putting them in an outdoor environment, engaging in outdoor activities that are distant from what they're doing, especially in this day and age. It's not in front of a computer. It's not in front of a TV. It's not 
playing a video game. It's not listening to music. It's being outside. It's a whole new level of experience.

Similarly, another district leader reflected how, over time, boys in Scouts become better equipped to handle the outdoors than "boys from the city." Without intending to, this leader identified a potential difference between the skills youth in Cub Scouts and Boy Scouts develop, as compared to their peers in the ScoutReach arm of BSA.

Another leader in this group noted how the "natural" component of Scouting may have a double meaning. He explained that youth in BSA are perceived as experiencing "natural learning," through being exposed to opportunities to learn and develop skills in the outdoors, and, as well, through being given opportunities to apply the skills they learn to real-life problem-solving tasks. In this leader's words:

They learn how to respect the outdoors and our natural resources... it gives them the opportunity to put into practice the positive training that they get at home, morals, principles, and all of that - where they actually get to be around a group of their peers, where they can put all of that into practice.

\section{"Having a moral ready"}

"Exemplary" leaders, more so than leaders in the other focus groups, focused their discussions on how they try to influence character in the youth they served. For instance, one leader noted to the others:

You guys have been in Scouting so long, obviously the folks in this room have that innately. If a boy came to you, you would know what to say. You'd have a story. You've have an answer. You'd have a moral for him.

Thus, one character development process in which these "exemplary" leaders felt well-equipped to engage was finding the moral in the stories and lessons they shared with youth, and clearly communicating this moral as part of their youth-leader relationships. Although this particular leader was confident in his experienced co-participants' abilities to infuse their conversations with youth with moral lessons, he was not so confident about other, less-experienced leaders' abilities to do so.

In addition, this leader and his co-participants shared stories of challenges they experienced in recruiting adult volunteers whom they considered to be models of good character for youth. Importantly, parent recruitment was a challenge mentioned by leaders across focus groups. However, "exemplary" leaders spent more time voicing concerns related to finding parent leaders whom they viewed as reflecting the character focus of BSA and modeling it for youth. As one leader shared: "We're trying. We're trying all different things to get the parents to stay honest, and be helpful." Describing the character-related challenges he observed in parent volunteers, another leader remarked: "'Do as I say' doesn't really fly in the Scouts. It's got to be 'do as I do.'" Despite noting these particular leadership challenges in BSA, and that BSA cannot be delivered without the volunteerism of parents who reflect "good" character, all "exemplary" leaders shared the belief that BSA was a successful character development program. Moreover, all "exemplary" leaders believed that the longer youth remained in BSA, the more character they developed. In the words of one leader: "The beauty of Boy Scouts is that the journey and the destination ought to have equal weight." 


\section{ScoutReach-Specific Findings}

The third Research Question focused on potential differences between ScoutReach leaders' experiences and views of how they influence the youth they serve compared to the perceptions articulated by "exemplary" and district-level leaders. Accordingly, we highlight some of the ScoutReach-specific findings from our analysis of variations in focus group data. We refer back to some of the excerpts presented above as we address how ScoutReach leaders' views of PYD in the youth they serve compare to views expressed by district and "exemplary" leaders. We focus on two main findings of differences between ScoutReach leaders' views and those of the other leaders, noting that other descriptions of PYD processes and perceived outcomes by ScoutReach leaders matched up with descriptions provided by district and "exemplary" leaders (e.g., of the role of scaffolding and leadership opportunities, as well as activity participation, in the development of positive youth outcomes). Specifically, through our analysis, we found that ScoutReach leaders' descriptions departed from those of other leaders when they:

1. described the details of their caring relationships with youth, and

2. described how the setting of ScoutReach affected implementation of the BSA program.

\section{ScoutReach Leaders' Perceptions of Caring Youth-Leader Relationships}

ScoutReach leaders specifically focused on the nurturing they provided to the youth through their youth-leader relationships as addressing a deficit, or in the words of one leader, the reality that for some youth in her pack "there were no men" in their lives outside of Scouting. Similarly, although all leaders addressed how Scouting tries to teach boys to aim high and follow through on their activities and goals, the importance of inspiring youth to become leaders and high-achieving young people, despite the odds they faced in their daily lives, was unique to descriptions provided by ScoutReach leaders. As one leader explained: "You are a role model for what they can achieve." Addressing the race-related challenges that her Scouts experienced, another leader explained that although there is an African American president, the youth in ScoutReach still resist believing that they, too, could be president one day.

Similarly, another leader noted: "It's like at my school, we have an assistant principal, Dr. Smith, you know, and when I first introduced him to the kids, he's like 'you don't have to have them call me Dr. Smith. They can call me Mr. Smith.' I was like, 'no, they need to know that a minority man can be a doctor."

Thus, these leaders explained that it was not common for these youth to see minority men becoming leaders and/or successful professionals. Perhaps, in contrast to the views of district and "exemplary" leaders, ScoutReach leaders viewed the relationships they developed with youth as not only contributing to their character development and other positive outcomes, but as opening their minds to more hopeful futures and possibilities, despite the systemic inequalities they experience in the U.S.

\section{ScoutReach Leaders' Views of Delivering BSA in Urban Philadelphia}

In addition to these nuances in ScoutReach leaders' descriptions of how they have tried to influence PYD, these leaders discussed challenges of delivering BSA to youth in an urban setting. One leader indicated that, because of the realities of being in an urban setting, there is more violence near the schools where she delivers the program and a lack of accessible natural surroundings.

These features of ScoutReach, she explained, pose barriers to leaders' facilitation of many of the activities for which Scouts are supposed to receive merit badges. As she noted: "We teach 
inner city, and it's really hard to go outside at all, it's a really dangerous area. We have been able to do other activities, like instead of going fishing, my co-leader and I print out pictures of fish." Thus, this leader attempts to compensate for the challenges posed by delivering Scouting in urban Philadelphia by encouraging her Scouts to "go fishing" in the classroom.

Despite these limitations of delivering the program in an urban area, other leaders acknowledged that it was because the program was provided in schools in downtown Philadelphia, that youth who are not typically "reached" by BSA had the opportunity to join the program. These leaders also identified that, because the program was delivered at schools (as compared to in churches and community centers, where non-ScoutReach packs typically meet), youth could be a part of BSA in safe and structured environments. One leader noted that she loves "the fact that [she] knows they're safe," acknowledging the risks they may encounter in their communities or if they were to be home alone after school. Thus, according to ScoutReach leaders, the urban components of ScoutReach provide both challenges to ScoutReach leaders' ability to deliver the BSA program with fidelity, but also appear to increase their confidence in the program as a much needed vehicle for promoting positive youth and character outcomes.

\section{Discussion}

The aim of this investigation was to contribute to the knowledge base about how diverse leaders within OST programs perceive their influences and programmatic influences on PYD and character outcomes in the youth they serve, and to examine these perceptions in reference to some of the existing literature about effective youth development programs. Although literature in the PYD field attests to the importance of OST programs for promoting PYD, and of the important roles that adult leaders play in these OST programs (Lerner, 2004), only a few studies have focused on leaders' perceptions of the PYD-promoting processes that take place in the OST programs of which they are a part (e.g., Carruthers \& Busser, 2000; King et al., 2005). Moreover, only a small body of research has explored whether different groups of leaders from across a national-youth serving organization have shared understandings of their positive influences on youth.

Accordingly, we conducted five focus groups with leaders in the COL of BSA, in the greater Philadelphia area. Research questions guiding our implementation of focus groups, and the components of the grounded theory analysis we conducted, included:

1. what are leaders' perceptions of their influences on positive outcomes in youth, and do they correspond to the extant literature about processes of influence in OST programs associated with effective practice (i.e., the "Big Three" attributes of youth development programs; Lerner, 2004)?;

2. what, if any, variations can be identified in leaders' descriptions of the ways in which they promote positive youth outcomes within the context of BSA?; and

3. given the recent innovation of ScoutReach as a vehicle of BSA program delivery to predominantly ethnic minority, urban youth, how do ScoutReach leaders' perceptions of the impact of BSA on positive youth outcomes compare to those of other leaders?

Through our analysis, we identified that leaders had shared understandings of the general processes through which they influenced PYD and character outcomes in Scouts, and that these understandings reflected much of what PYD scholars write about in the literature and refer to as "the Big Three" (Lerner, 2004). We specifically identified that leaders understand themselves to influence positive youth outcomes in the context of BSA through:

1. engaging in "caring" relationships with Scouts; 
2. providing Scouts with opportunities to learn new skills and scaffold, or "lead," younger peers' skill development; and

3. providing opportunities for Scouts to apply these skills during Scout meetings, in "natural learning environments," and in other contexts, such as schools.

Through fostering these processes in the context of the Scouting program, each set of leaders in this study agreed that they contribute to the promotion of multiple positive outcomes in the Scouts they serve, including enhanced self-confidence, leadership skills, self-regulation skills, and academic competencies. These leaders also shared the belief that components of the BSA program (e.g., the merit badge system and Scout Law), and the ways in which leaders deliver this program to Scouts (e.g., explaining the meaning behind the merit badge system and each attribute in the Scout Law), contribute to youth enacting the skills they gain in Scouting and in other contexts (e.g., at home and school).

Based on analyses of leaders' focus group discussions, we, thus, generated some evidence suggesting that BSA in the COL is successful in promoting PYD through facilitating supportive youth-leader relationships and providing opportunities for youth skill development and skill application in valued activities. Moreover, we learned that, despite the scope of BSA in greater Philadelphia and the different histories and experiences of leaders, there is shared knowledge about how leaders in this program should and do influence youth. In addition, we learned that leaders' own theories about how they influence youth are consistent with PYD literature, and enhance this knowledge by contextualizing it in the setting of this particular OST program.

In their own words, leaders in this study articulated that the "caring" relationships they form with youth are one of the most important features of BSA programs, and one of the most influential ways in which they promote positive outcomes in youth. Leaders also provided numerous examples of the skill-building activities they facilitate for youth, and the outcomes they believe to be promoted through these activities. Finally, leaders shared many positive stories from their own experiences about how they observed positive changes in youth that they understood as resulting from their participation in Scouting activities and applying the skills to additional BSA experiences and in other contexts. ScoutReach and district leaders provided examples of how youth gained confidence in themselves and enhanced their abilities to better regulate their behaviors and reach goals through being exposed to the positive and encouraging environment of BSA.

In addition to having shared understandings about the ways in which they influence youth, leaders across focus groups presented similar examples of the barriers they encountered to delivering the BSA program. For example, leaders across groups described the frustration of low parent participation in Scouting. For "exemplary" leaders, however, frustration with parents also related to their observations that parents were not equally equipped to model character for youth. ScoutReach leaders emphasized challenges of modeling additional positive outcomes for youth, such as hopeful future orientations. These leaders described how they modeled and taught youth that they should and could have high aspirations for their futures. However, this message was difficult for some Scouts, given all the challenges they experience as part of their day-to-day lives.

Thus, differences between leaders' descriptions of how they promoted PYD among the youth they served reflected individual variation in these youth, as well as individual variation in leaders' backgrounds and knowledge bases. As scholars in the PYD field posit, the goal of youth development research is to understand what mutually beneficial person-context relations 
promote what positive outcomes, and for what youth (Bornstein, 2006; Lerner et al., 2015). Uncovering the diversity of youth experiences and PYD processes is a key aim of PYD research. This study suggests that this aim is also a key consideration of youth-serving practitioners in high-quality programs. However, findings also suggest that more research is needed about how to deliver a standardized national OST program curriculum, such as the BSA curriculum, in a way that it sensitive to and addresses these instances of diversity. Needs assessments could provide BSA with a sense of what additional resources are necessary for an optimized program to be implemented in urban communities. Additional systematic support, for example, such as a ScoutReach specific alternative activities handbook (i.e., an urban Scouter's guidebook) with options that match the resources of urban contexts, could be used to augment the standard BSA curriculum. Although we have heard of such manuals being used at some point by different urban Scouting programs in the U.S., no such resource was circulated throughout BSA programs at the national level or within the COL during this investigation (BSA, 2014).

The importance of such guidance and flexibility in program implementation in urban, highpoverty contexts has been shown to be effective for other youth programs such as the Youth Engaged in Leadership and Learning program (Anyon, \& Naughton, 2003). Various ScoutReach leaders could contribute to the urban Scouter's guidebook, sharing modified programs such as "going fishing in the classroom," in which ScoutReach leaders taught seemingly out-of-reach Scouting skills by thorough planning and ingenuity.

Although ScoutReach leaders were well aware of the needs of the youth they serve, and of how these needs may be similar to and different from the needs of Scouts in other arms of BSA, they were tasked with implementing the same BSA curriculum in their urban after-school program setting that district leaders identified as designed to be delivered in the outdoors. ScoutReach leaders acknowledged, however, that the other facets of the BSA curriculum were a good fit with the needs of the youth they served, and that their Scouts would not be exposed to such a program if not for the after-school component of ScoutReach. Specifically, ScoutReach leaders noted that their Scouts, who would likely be excluded from Scouting due to a lack of "safe" spaces for Scout meetings in their communities, are being exposed to some of the character-development components of the program because it is being delivered in schools in downtown Philadelphia.

Thus, despite the poor fit of the "natural learning" component of Scouting to the setting in which ScoutReach is being delivered, ScoutReach leaders all expressed appreciation for the existence of ScoutReach, and confirmed that, through this program, ScoutReach youth were being exposed to PYD-promoting processes and outcomes. ScoutReach leaders also confirmed that the youth they serve are developing some of the same positive outcomes as youth in other arms of BSA (e.g., life skills, increased self-confidence and perseverance), as well as other outcomes that may be more specific to the needs of the youth in ScoutReach, such as more hopeful future orientations.

Therefore, from ScoutReach leaders, as well as district and "exemplary" leaders, we learned that they believe that the main components of BSA - caring relationships with leaders, skillbuilding activities (e.g., building birdcages), and opportunities to apply newly developed skills to real-life problems (e.g., supplying first aid care during recess) - are successfully being delivered to youth in the program, despite socio-demographic and contextual differences. We also learned that some of the observed positive influences of BSA are influencing youth outcomes even when youth are not attending BSA meetings or activities. In particular, leaders shared the 
view that, because of Scouting, youth are doing their best to succeed in other facets of their lives, and are learning to persevere and accomplish their goals.

\section{Future Directions}

Leaders' descriptions have enhanced understanding of the processes through which positive outcomes in youth from a diversity of backgrounds may be promoted in BSA. In addition, we have a better understanding of some of the distinct challenges leaders (within the same youthserving organization) experience to promoting these strengths in the youth they serve. The knowledge gained from leaders also suggests that the field of PYD is moving in the right direction as it attempts to understand the diverse processes through which youth come to experience thriving and well-being, despite challenges they may encounter in different facets of their lives. Although some leaders described how Scouting promotes positive outcomes through preventing negative behaviors and, thus, took more of a deficit orientation in their description of the influence of BSA on youth, most of the examples leaders gave focused on how Scouting cultivates youth strengths. We suggest, therefore, that leaders in this study likewise reflected an orientation to influencing youth outcomes that is in line with PYD research on high-quality OST programs (e.g., Lerner, 2004).

The findings from this study also support previous research with youth from lower-SES backgrounds, highlighting the importance of providing (and sustaining) access to high-quality youth programs for this population (Mahoney, Vandell, Simpkins, \& Zarrett, 2009). In addition, this study suggests that providing youth from "higher-risk" communities with caring relationships with adults not only enables youth to "believe in themselves," and to "hold themselves to high standards," but may impact their future orientations. Hopeful future orientations are associated with important life outcomes for youth of color and youth from lowSES backgrounds (Diemer \& Blustein, 2007; Schmid, \& Lopez, 2010). Therefore, future research should continue to investigate the extent to which OST programs may influence hopeful future orientation among youth of color, and youth from low-SES communities.

In this investigation, we also learned that leaders across different arms of BSA identify leadership development as an important process and outcome related to the positive development of the youth in BSA, as they move through Boy Scouts (between $6^{\text {th }}$ and $12^{\text {th }}$ Grade). Researchers in the PYD field have also identified that leadership development is strongly associated with PYD across a diversity of young people (Lerner, 2004). Unfortunately, for youth in the ScoutReach arm of BSA, Boy Scouts is only available on a limited basis (i.e., the elementary school years). Findings from this study, thus, suggest that providing adolescents with leadership development opportunities should be as much of a priority as providing these youth with access to nurturing relationships and opportunities for other types of skill development when they are in elementary school.

However, these implications for future research must be tempered in light of the limitations of the present research. One limitation is that two of the three groups of leaders (district leaders and "exemplary" leaders) volunteered with young people in Cub and Boy Scouts, that is, with youth in elementary school and middle/high school, respectively. Thus, leaders reflected on PYD-related processes and outcomes across different age groups of youth, rather than solely focusing on the development of youth in middle childhood or during adolescence. However, leaders typically specified the age group of youth to which they were referring throughout their descriptions of PYD in BSA. They were aware that the overall CAMP Study, of which this investigation is a part, is a longitudinal examination of positive development in Cub Scouts. 
Nevertheless, more data from leaders who work only with Cub Scouts could help us identify some of the leader-generated PYD processes that are perceived as being specific to Cub Scouts, the population of interest in the larger CAMP Study.

An additional limitation of this study is that ScoutReach leaders are paid leaders in BSA, whereas district leaders and "exemplary" leaders are volunteers. This variation could have influenced leaders' descriptions of the strengths and challenges they identified when they described the ways in which they deliver BSA to youth. It is possible, for example, that ScoutReach leaders were reluctant to divulge information about challenges they confront in BSA, due to their financial reliance on their positions as paid BSA leaders. We did not allow BSA staff to be present during the ScoutReach focus groups, explaining that their responses would be confidential. Nevertheless, it is possible that their positions as paid employees in the COL factored into the discussions that ensued in these groups. Similarly, a collaborator on the CAMP Study, who was also a COL staff member, was present for the focus group with "exemplary" leaders, which may have influenced the information they divulged. It is possible that a different constellation of focus group facilitators and participants would have yielded more (or less) information from leaders about the ways in which they influence PYD in Scouts, and about challenges they experience therein.

However, because focus groups leverage group discussions to generate knowledge and information, the data generated is always a reflection of the characteristics of participants and of the group dynamics between them (Kitzinger, 1995). Nevertheless, and despite the information gained from this study, the influence of the individual characteristics of participants on the data presented suggest that our findings are not generalizable to all leaders in the COL, or to all leaders in high-quality OST programs in the U.S. However, they do provide important information from a sample of leaders in the COL about how they may influence the youth they serve. In addition, future studies can now triangulate the results of this investigation with quantitative data we have collected from Scouts who have also participated in the CAMP Study over the last two and a half years, including 4-waves of their self-reported positive and character related outcomes (e.g., helpfulness, friendliness, rule-following, see Hilliard et al., 2014 for more information). Through triangulating these data, we will be able to generate holistic information about how positive outcomes may develop among Scouts in the COL. In addition, we will be able to triangulate the current findings with youth interviews from the CAMP Study to determine whether leaders' and Scouts' perceptions of youth-leader relationships and the influences of BSA programs on youth are commensurate with one another.

\section{Conclusions}

We believe that the information generated through these focus groups provide valuable and contextualized information about how leaders in a national youth-serving organization influence positive outcomes in the youth they serve. We have also identified important information about how individual and group differences may factor into the implementation of a national OST program. Furthermore, the findings from this study suggest that, when these differences are attended to and leveraged, more information about what processes promote what specific positive outcomes, for what youth, and in what settings, can be gleaned and put into action.

The information we generated suggests that, whereas BSA is, indeed, a high-quality youth development program that is making a real difference in the lives of the youth it serves (e.g., through promoting "the Big Three," Lerner, 2004), there is still room for improvement. By 
adapting curricula and activities to better meet the challenges, and match the strengths, experienced by the increasingly diverse youth who participate in the program, BSA and other national OST programs may be more effective at enabling youth to thrive, and, thus, to positively contribute to themselves, to others, and to society (Lerner et al., 2015).

Acknowledgement: This research was supported by a grant to Richard M. Lerner from the John Templeton Foundation. Address correspondence to: Rachel M. Hershberg, 308 Lincoln Filene Hall, Tufts University, Medford, MA 02155. Email: rachel.hershberg@tufts.edu.

\section{References}

Anyon, Y., \& Naughton, S. (2003). Youth Empowerment: The Contributions and Challenges of Youth-Led Research in a High-Poverty, Urban Community, 1-8.

Benson, P.L., Scales, P.C., \& Syvertsen, A.K. (2011). The contribution of the developmental assets framework to positive youth development theory and practice. Advances in child development and behavior, 41, 197-230.

Blum, R.W. (2003). Positive youth development: A strategy for improving health. In. F. Jacobs, D. Wertlieb, \& R.M. Lerner (Eds.), Handbook of applied developmental science: Vol. 2.

Promoting positive child, adolescent, and family development through research, policies, and programs (pp. 237-252). Thousand Oaks, CA: Sage.

Bornstein, M.H. (2006). Parenting science and practice. In K.A. Renninger, I.E. Sigel (Vol. Eds.), Handbook of child psychology, Vol. 4: Child psychology in practice (6 ${ }^{\text {th }}$ ed., pp. 893-949).

Editors-in-Chief: W. Damon, \& R.M. Lerner. Hoboken, NJ: Wiley.

Boy Scouts of America. (2014). Retrieved September 2nd, 2014, from http://www.scouting.org/

Braun, V., \& Clarke, V. (2006). Using thematic analysis in psychology. Qualitative Research in Psychology, 3(2), 77-101.

Carruthers, C.P., \& Busser, J.A. (2000). A qualitative outcome study of Boys and Girls Club program leaders, club members, and parents. Journal of Park and Recreation Administration, $18(1), 50-67$.

Charmaz, K. (2006). Constructing grounded theory: A practical guide through qualitative analysis. Thousand Oaks, CA: Sage Publications.

Corbin, J., \& Strauss, A. (2008). Basics of qualitative research: Techniques and procedures for developing grounded theory. Thousand Oaks, CA: Sage Publications.

Diemer, M.A., \& Blustein, D.L. (2007). Vocational hope and vocational identity: Urban adolescents' career development. Journal of Career Assessment, 15(1), 98-118.

Harris Interactive (2003). Volunteer outcomes study. Irving, TX: Boy Scouts of America National Office.

Hilliard, L.J., Hershberg, R.M., Wang, J., Bowers, E.P., Chase, P.A., Champine, R.B., ...Ferris, K. 
(20142014). Program innovations and character in Cub Scouts: Findings from year 1 of a mixed-methods, longitudinal study. Journal of Youth Development, 9, 4-30.

Jang, S.J., Johnson, B.R., \& Kim, Y. (2012). Eagle Scouts: Merit beyond the badge. Institute for Studies of Religion, Baylor University. Retrieved from http://www.orgsites.com/oh/troop447/EagleScoutMeritBeyondtheBadge.pdf

King, P.E., Dowling, E.M., Mueller, R.A., White, K., Schultz, W., Osborn, P., ...Scales, P.C. (2005). Thriving in adolescence: The voices of youth-serving practitioners, parents, and early and late adolescents. The Journal of Early Adolescence, 25(1), 94-112.

Kitzinger, J. (1995). Qualitative research. Introducing focus groups. British Medical Journal, 311, 299-302.

Larson, R.W. (2000). Toward a psychology of positive youth development. American Psychologist, 55(1), 170-183.

Larson, R.W. (2006). Positive youth development, willful adolescents, and mentoring. Journal of Community Psychology, 34(6), 677-689.

Lerner, R.M. (2004). Liberty: Thriving and civic engagement among America's youth. Thousand Oaks, CA: Sage Publications.

Lerner, R.M., Alberts, A.E., Jelicic, H., \& Smith, L.M. (2006). Young people are resources to be developed: Promoting positive youth development through adult-youth relations and community assets. In E.G. Clary \& J.E. Rhodes (Eds.), Mobilizing adults for positive youth development: Strategies for closing the gap between beliefs and behaviors (pp. 19-39). Minneapolis, MN: Search Institute.

Lerner, R.M., Lerner, J.V., \& Benson, J.B. (2011). Positive youth development: Research and applications for promoting thriving in adolescence. In R.M. Lerner, J.V. Lerner, \& J.B. Benson (Eds.), Advances in Child Development and Behavior.

Lerner, R.M., Lerner, J.V., Bowers, E., \& Geldhof, G.J. (2015). Positive youth development: A relational developmental systems model. In W.F. Overton \& P.C. Molenaar (Eds.), Theory and Method. Volume 1 of the Handbook of Child Psychology and Developmental Science (7th ed.). Editor-in-chief: R.M. Lerner. Hoboken, NJ: Wiley.

Lerner, R.M., \& Thompson, L.S. (2002). Promoting healthy adolescent behavior and development: Issues in the design and evaluation of effective youth programs. Journal of Pediatric Nursing, 175), 338-344.

Louis Harris \& Associates. (1998). A year in the life of a Cub Scout...Boy Scout... Venturer: Strengthening youth, families, and neighborhoods. New York, NY: Louis Harris \& Associates, Inc. Retrieved from http://www.scouting.org/FILESTORE/marketing/pdf/02-303.pdf/

Mahoney, J.L., Vandell, D.L., Simpkins, S., \& Zarrett, N. (2009). Adolescent out-of-school activities. In R.M. Lerner \& L. Steinberg (Eds.), Handbook of adolescent psychology: Contextual influences on adolescent development (3rd ed., Vol. 2, pp. 228-267). Hoboken, NJ: Wiley. 
Morrow, S.L. (2005). Quality and trustworthiness in qualitative research in counseling psychology. Journal of counseling psychology, 52(2), 250.

Polson, E.C., Kim, Y.I., Jang, S.J., Johnson, B.R., \& Smith, B. (2013). Being prepared and staying connected: Scouting's influence on social capital and community involvement. Social Science Quarterly, 94, 758-776.

Rhodes, J.E., \& Lowe, S.R. (2009). Mentoring in adolescence. In R.M. Lerner \& L. Steinberg (Eds.), Handbook of adolescent psychology: Vol. 2. Contextual influences on adolescent development ( ${ }^{\text {rd }}$ ed., pp. 152-190). Hoboken, NJ: Wiley.

Rhodes, J.E., Spencer, R., Keller, T.E., Liang, B., \& Noam, G. (2006). A model for the influence of mentoring relationships on youth development. Journal of Community Psychology, 34(6), 691-707.

Roth, J.L., \& Brooks-Gunn, J. (2003). Youth development programs: Risk, prevention and policy. The Journal of Adolescent Health: Official Publication of the Society for Adolescent Medicine, 32, 170-182.

Schmid, K.L., \& Lopez, S.J. (2010). Positive pathways to adulthood: the role of hope in adolescents' constructions of their futures. Advances in Child Development and Behavior, 41, 69-88.

Strauss, A., \& Corbin, J. (1998). Basics of qualitative research: Techniques and procedures for developing grounded theory. Thousand Oaks, CA: Sage.

Sullivan, P.J., \& Larson, R.W. (2010). Connecting youth to high-resource adults: Lessons from effective youth programs. Journal of Adolescent Research, 25(1), 99-123.

Theokas, C., Lerner, J.V., Phelps, E., \& Lerner, R.M. (2006). Cacophony and change in youth after school activities: Findings from the 4-H study of positive youth development. Journal of Youth Development, 1(1),

Vandell, D.L., Larson, R.W, Mahoney, J.L., \& Watts, T.W. (2015). Children's organized activities. In M.H. Bornstein \& T. Leventhal (Eds.), Handbook of child psychology and developmental science, Vol. 4: Ecological settings and processes in developmental systems (7th ed., pp. 305344). Editor-in-chief: R.M. Lerner. Hoboken, N.J.: Wiley.

von Eye, A., Lerner, J.V., Arbeit, M.R., Weiner, M.B., Chase, P., \& Agans, J.P. (2011). The role of ecological assets in positive and problematic developmental trajectories. Journal of Adolescence, 34(6), 1151-1165.

(C) Copyright of Journal of Youth Development Bridging Research and Practice. Content may not be copied or emailed to multiple sites or posted to a listserv without copyright holder's express written permission. Contact Editor at: patricia.dawson@oregonstate.edu for details. However, users may print, download or email articles for individual use.

ISSN 2325-4009 (Print); ISSN 2325-4017 (Online) 